\title{
Clinical significance of multiple systolic clicks from Starr-Edwards prosthetic aortic valves
}

\author{
EDWARD B. SIMON, MORRIS N. KOTLER, BERNARD L. SEGAL, AND \\ WAYNE PARRY
}

From the Cardiovascular Institute, Hahnemann Medical College and Hospital, Philadelphia, Pennsylvania, U.S.A.

The use of echocardiography, phonocardiography, and spectroanalysis has enhanced the ability to detect prosthetic valve dysfunction even before the onset of symptoms in many patients. Reduction in the intensity of the opening and closing clicks and the appearance of new murmurs have been the most frequently reported observations in predicting prosthetic valve dysfunction. Simultaneous echocardiography, phonocardiography, and spectroanalysis were performed on 31 patients with Starr-Edwards prosthetic aortic valves. Eighteen patients had valves with metal (titanium or 'stellite') poppets, and 13 had valves with non-metal (silastic) poppets. In all patients with normally functioning valves with metal poppets, there were multiple systolic clicks on auscultation and confirmed by phonocardiography and spectroanalysis. In none of the patients with non-metal poppets were there clicks other than those associated with the normal opening and closing movements of the poppets. Three of the 18 patients with metal poppets did not manifest multiple systolic clicks, yet the cut-off frequencies on spectroanalysis for opening and closing clicks in 1 of these patients were normal. Prosthetic valve dysfunction was shown in all 3 patients by cardiac catheterisation or at operation. We conclude that multiple systolic clicks are normal for patients with Starr-Edwards prosthetic aortic valves with metal (titanium or 'stellite') poppets, and that the absence of multiple systolic clicks may indicate prosthetic valve dysfunction even when the cut-off frequencies of the opening and closing clicks are normal.

Because of the large number and different types of prosthetic valves, it is essential that the clinician be familiar with the normal characteristics of each type. Spectroanalysis is a fairly new technique used to complement the information obtained by echocardiographic and phonocardiographic examination (Winters et al., 1967; Hylen et al., 1969; Waxler et al., 1973; Gordon et al., 1974). This paper compares two types of Starr-Edwards prosthetic aortic valves-one with a metal (titanium or 'stellite') poppet and one with a non-metal (silastic) poppetand shows how spectroanalysis can distinguish between the two valve types and indicate valve dysfunction as well.

\section{Subjects and methods}

Three groups of patients were studied. Group 1 comprised 15 patients with normally functioning Starr-Edwards prosthetic aortic valves with metal (titanium or 'stellite') poppets (Table 1). Group 2 comprised 3 patients with Starr-Edwards prosthetic Received for publication 13 December 1976 aortic valves with metal poppets that had malfunctioned (Table 2). Group 3 comprised 13 patients with Starr-Edwards prosthetic aortic valves with non-metal (silastic) poppets with normal function (Table 3).

Echocardiographic examinations were carried out with an Ekoline 20 (Smith Kline Instruments, Inc., Palo Alto, Calif.) with a $2.25 \mathrm{MHz}$ internal-focus transducer half an inch in diameter. Strip chart recordings of $\mathrm{M}$-mode scan were made with a ContinuTrace multichannel recorder (Irex Medical Systems, Mahwah, N.J.) or a fibreoptic multichannel physiological recorder (Kent Cambridge Medical Limited, Ossining, N.Y.). The patients were examined while they were recumbent, with the torso raised $30^{\circ}$, or in the partial left lateral decubitus position. The transducer was placed in the third or fourth intercostal space along the left sternal border until the typical pattern of the anterior mitral leaflet was identified. The transducer was slowly rotated medially and superiorly until echoes from the prosthetic aortic valve were obtained. In our institution echoes from the poppet 
Table 1 Patients with Starr-Edwards prosthetic aortic valve with metal (titanium or 'stellite') poppets with normal valve function and multiple systolic clicks

\begin{tabular}{rrl}
$\begin{array}{l}\text { Case } \\
\text { No. }\end{array}$ & $\begin{array}{l}\text { Frequency }(\mathrm{Hz}) \text { of opening } \\
\text { and closing clicks }\end{array}$ & Other valvular abnormalities \\
\hline 1 & 25000 & Mild mitral stenosis \\
2 & 2000 & Beall mitral prosthesis \\
3 & 2000 & Beall mitral prosthesis \\
4 & 2000 & None \\
5 & 16000 & None \\
6 & 16000 & None \\
7 & 16000 & None \\
8 & 4000 & None \\
9 & 16000 & None \\
10 & 2000 & None \\
11 & 8000 & Mitral stenosis with \\
& & commissurotomy \\
12 & 4000 & Uncertain \\
13 & 16000 & Uncertain \\
14 & 16000 & None \\
15 & 20000 & Beall mitral prosthesis \\
\end{tabular}

Table 2 Patients with Starr-Edwards prosthetic aortic valves with metal (titanium or 'stellite') poppets with valve dysfunction and absent multiple systolic clicks

\begin{tabular}{|c|c|c|c|}
\hline $\begin{array}{l}\text { Case } \\
\text { No. }\end{array}$ & $\begin{array}{l}\text { Other valvular } \\
\text { abnormalities }\end{array}$ & $\begin{array}{l}\text { Frequencies of } \\
\text { opening and closing } \\
\text { clicks (in } \mathrm{Hz} \text { ) }\end{array}$ & Comments \\
\hline 1 & None & 16000 & $\begin{array}{l}68 \mathrm{mmHg} \text { gradient across } \\
\text { prosthetic aortic valve } \\
\text { at catheterisation; } \\
\text { patient subsequently } \\
\text { died; necropsy showed } \\
\text { thrombus on valve }\end{array}$ \\
\hline 2 & $\begin{array}{l}\text { Beall mitral } \\
\text { prosthesis }\end{array}$ & $\begin{array}{l}\text { Opening click, } 250 \\
\text { Closing click, } 1000\end{array}$ & $\begin{array}{l}\text { Cardiac catheterisation } \\
\text { showed poppet } \\
\text { displaced laterally by } \\
\text { thrombus }\end{array}$ \\
\hline 3 & None & 1000 & $\begin{array}{l}90 \text { mmHg gradient across } \\
\text { prosthetic valve at } \\
\text { cardiac catheterisation; } \\
\text { thrombus on struts seen } \\
\text { at surgery }\end{array}$ \\
\hline
\end{tabular}

Table 3 Patients with Starr-Edwards prosthetic aortic valves with non-metal (silastic) poppets with normal valve function

\begin{tabular}{cll}
\hline $\begin{array}{l}\text { Case } \\
\text { No. }\end{array}$ & $\begin{array}{l}\text { Frequency of } \\
\text { opening and closing } \\
\text { clicks }(\mathrm{Hz})\end{array}$ & Other valvular abnormalities \\
\hline 1 & 1000 & None \\
2 & 2000 & None \\
3 & 2000 & None \\
4 & 2000 & None \\
5 & 2000 & Uncertain \\
6 & 1000 & Mitral commissurotomy with restenosis \\
7 & 2000 & None \\
8 & 1000 & None \\
9 & 1000 & None \\
10 & 6000 & Mild restenosis of mitral valve; \\
& & tricuspid Starr-Edwards silastic valve \\
11 & 3000 & Mitral and tricuspid Starr-Edwards \\
& & silastic valves \\
12 & 2000 & None \\
13 & 2000 & Mild mitral regurgitation \\
\hline
\end{tabular}

were obtained in the majority of instances. It was occasionally necessary to place the transducer in the right supraclavicular fossa to obtain the clearest possible echoes from the prosthetic aortic valve. Phonocardiography was performed with a suction microphone placed at the apex of the heart.

Spectroanalysis is a method of evaluating sound emission by monitoring sound frequency and intensity (Waxler et al., 1973; Gordon et al., 1974). It has been used extensively in modern industry to test the function of certain machinery. The function of prosthetic valves can also be evaluated by determining the frequency profile of the opening and closing clicks for each type of prosthetic valve (Gordon et al., 1974). A normally functioning prosthesis will produce opening and closing sounds at specific frequencies, depending upon the individual characteristics of that particular valve. Valve dysfunction, such as that caused by thrombus formation or tissue ingrowth (Najmi and Segal, 1965; Herr et al., 1967; Hylen et al., 1968, 1969, 1970; Delman, 1972), will be shown by a lower frequency than expected for that particular valve. Frequency profiles have been established in the laboratory at our institution for Starr-Edwards prosthetic valves with metal (titanium and 'stellite') and non-metal (silastic) poppets (Table 4) (Gordon et al., 1974).

The spectroanalysis instrumentation is a combination of a filter system and a system for indicating the relative energy that is passed through the filter system (Gordon et al., 1974). This system consists of a transducer, a preamplifier, an octave bandanalyser with an output (decibel) meter, an oscilloscope, and an electrocardiograph (Gordon et al., 1974). The procedure consists of using a cylindrical transducer (General Radio Company, Concord, Massachusetts) with a flat frequency response from 20 to $25000 \mathrm{~Hz}$ which serves as a vibration pick-up device. The transducer was placed in the third and fourth left intercostal space 2 or $3 \mathrm{~cm}$ lateral to the left sternal border and was attached to an octave band noise analyser (GR type $1558 \mathrm{BP}$ or GR type 1564A). An octave band is the interval between two sounds having a basic frequency ratio

Table 4 Frequency profile of Starr-Edwards prosthetic aortic valves

\begin{tabular}{|c|c|c|c|c|}
\hline \multirow{2}{*}{$\begin{array}{l}\begin{array}{l}\text { Prosthetic } \\
\text { valve type }\end{array} \\
\text { Metal poppet } \\
\text { ('stellite' or } \\
\text { titanium) } \\
\text { Silastic poppet }\end{array}$} & \multicolumn{2}{|c|}{$\begin{array}{l}\text { Frequency of aortic } \\
\text { opening click }(\mathrm{Hz})\end{array}$} & \multicolumn{2}{|c|}{$\begin{array}{l}\text { Frequency of aortic } \\
\text { closing click }(\mathrm{Hz})\end{array}$} \\
\hline & $\begin{aligned}> & 4000 \\
& 1000-4000 \\
< & 1000 \\
> & 2000 \\
& 500-2000 \\
< & 500\end{aligned}$ & $\begin{array}{l}\text { Normal } \\
\text { Borderline } \\
\text { Abnormal } \\
\text { Normal } \\
\text { Borderline } \\
\text { Abnormal }\end{array}$ & $\begin{aligned}> & 4000 \\
& 1000-4000 \\
< & 1000 \\
> & 2000 \\
& 500-2000 \\
< & 500\end{aligned}$ & $\begin{array}{l}\text { Normal } \\
\text { Borderline } \\
\text { Abnormal } \\
\text { Normal } \\
\text { Borderline } \\
\text { Abnormal }\end{array}$ \\
\hline
\end{tabular}


of $2: 1$. The effective band for $1000 \mathrm{~Hz}$, for example, would be from 707 to $1414 \mathrm{~Hz}$. The centre band frequencies ranged from 25 to $25000 \mathrm{~Hz}$.

\section{Results}

Of the 18 patients with the Starr-Edwards prosthetic aortic valves with a metal poppet (titanium or 'stellite'), there were multiple systolic clicks in 15 , as shown by phonocardiography and spectroanalysis. On auscultation, these clicks sound very much like the rapid fire from an automatic machine gun. The opening and closing sounds of each valve vary from $1000 \mathrm{~Hz}$ to $25000 \mathrm{~Hz}$ (Tables 1 , 2, and 3 ). The very high frequency sounds (greater than $15000 \mathrm{~Hz}$ ) are recorded by spectroanalysis but are not within the range of auscultation by the human ear.

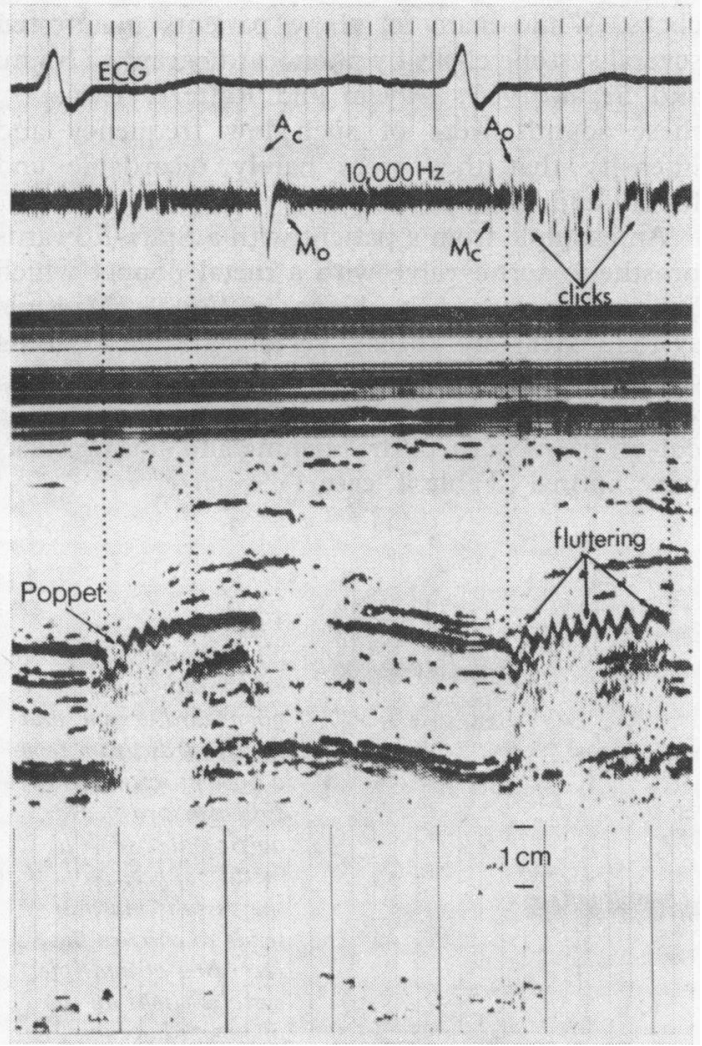

Fig. 1 Simultaneous spectroanalysis, echocardiogram, and electrocardiogram from a patient with a StarrEdwards prosthetic aortic valve with a metal poppet and a Beall mitral valve with a pyrolite disc. AO, aortic opening click; $A C$, aortic closing click; MO, mitral opening click; $M \mathcal{O}$, mitrsl closing click. Time lines are $40 \mathrm{~ms}$.

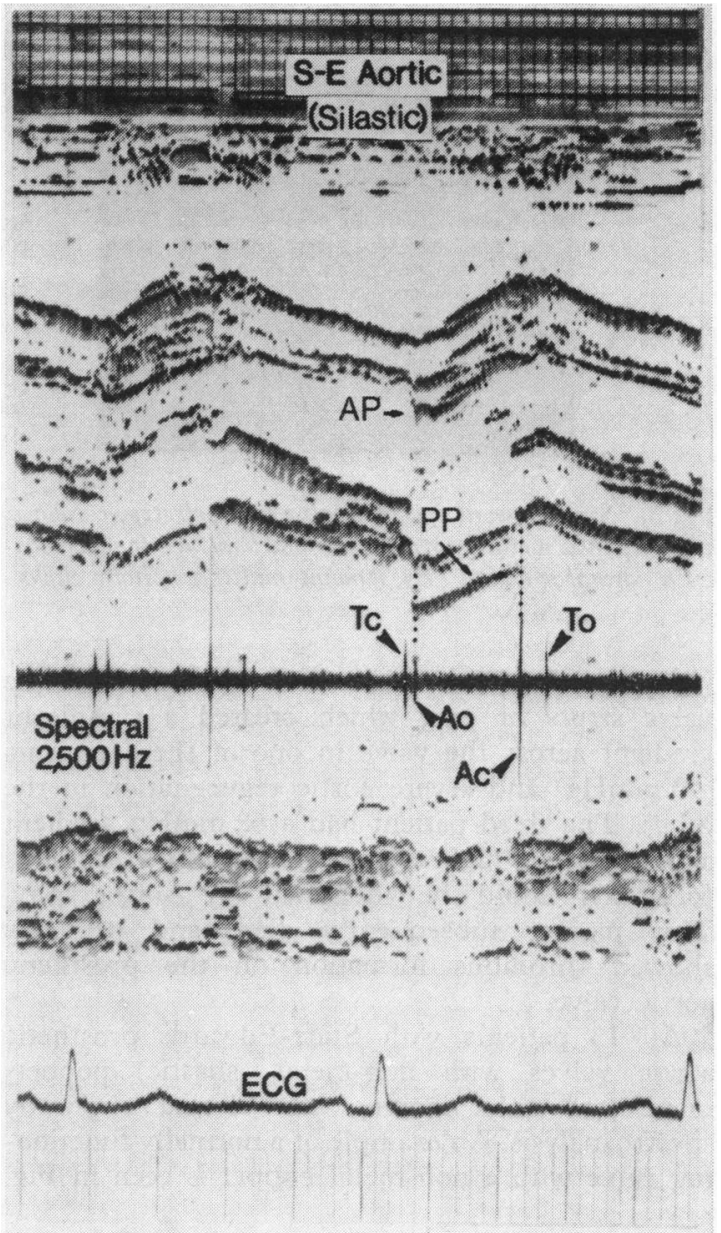

Fig. 2 Simultaneous spectroanalysis, echocardiogram, and electrocardiogram from a patient with StarrEdwards prosthetic aortic and tricuspid valves with silastic poppets. $A O$, aortic opening click; $A C$, aortic closing click; TO, tricuspid opening click; TC, tricuspid closing click; $A P$, anterior poppet; $P P$, posterior poppet. Time lines are $40 \mathrm{~ms}$.

An example of the multiple systolic clicks from a patient with a Starr-Edwards prosthetic aortic valve with a metal (titanium or 'stellite') poppet is seen in Fig. 1. Simultaneous spectroanalysis, echocardiogram, and electrocardiogram are represented. Numerous systolic clicks can readily be identified and are coincident with the fluttering motion of the metal poppet as shown by the echocardiogram.

Of the 18 patients with Starr-Edwards prosthetic aortic valves with metal poppets, 3 did not manifest multiple systolic clicks (Table 2). Subsequent cardiac catheterisation or surgical exploration indicated valve dysfunction. Two of the patients 
A.

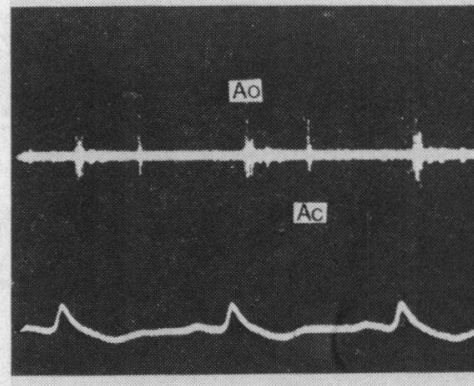

B.

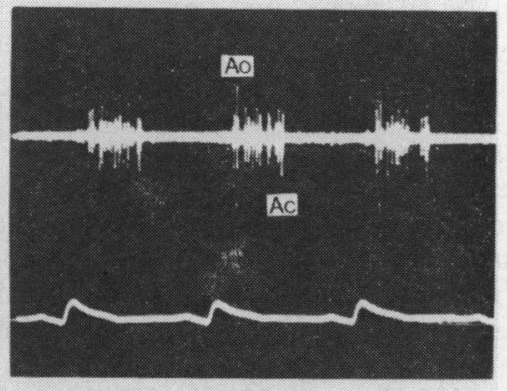

Fig 3 Simultaneous spectroanalysis and electrocardiogram from a patient with a Starr-Edwards prosthetic aortic valve with a metal poppet which had malfunctioned $(A)$, showing absence of multiple systolic clicks, and from a patient with normal function (B) showing multiple systolic clicks. $A C$, aortic closing click; $A O$, aortic opening click

were found to have thrombus formation on the valve struts or ring which created a significant gradient across the valve in one of these patients $(90 \mathrm{mmHg})$ and severe aortic regurgitation in the other. The third patient had a $68 \mathrm{mmHg}$ gradient across the prosthetic valve, but no definite thrombus formation could be identified by aortography. This patient subsequently died, and necropsy showed thrombus formation on the prosthetic aortic valve.

All 13 patients with Starr-Edwards prosthetic aortic valves with non-metal (silastic) poppets manifested only opening and closing clicks by spectroanalysis. An example of a normally functioning valve with a non-metal poppet is seen in Fig.
2 ; such a valve produced only opening and closing clicks. While many of these patients manifested several systolic clicks by phonocardiography (Najmi and Segal, 1965; Dayem and Raftery, 1966a, b), these sounds were of such low frequency and intensity that they were barely recordable and hardly audible.

An example from a patient with a Starr-Edwards prosthetic aortic valve with a metal poppet which had malfunctioned is shown in Fig. 3. Multiple systolic clicks are absent, yet opening and closing clicks are clearly recorded. In 1 of the 3 patients with malfunctioning valves with metal poppets, the cut-off frequencies of the opening and closing clicks were normal (Table 2, case 1 ).

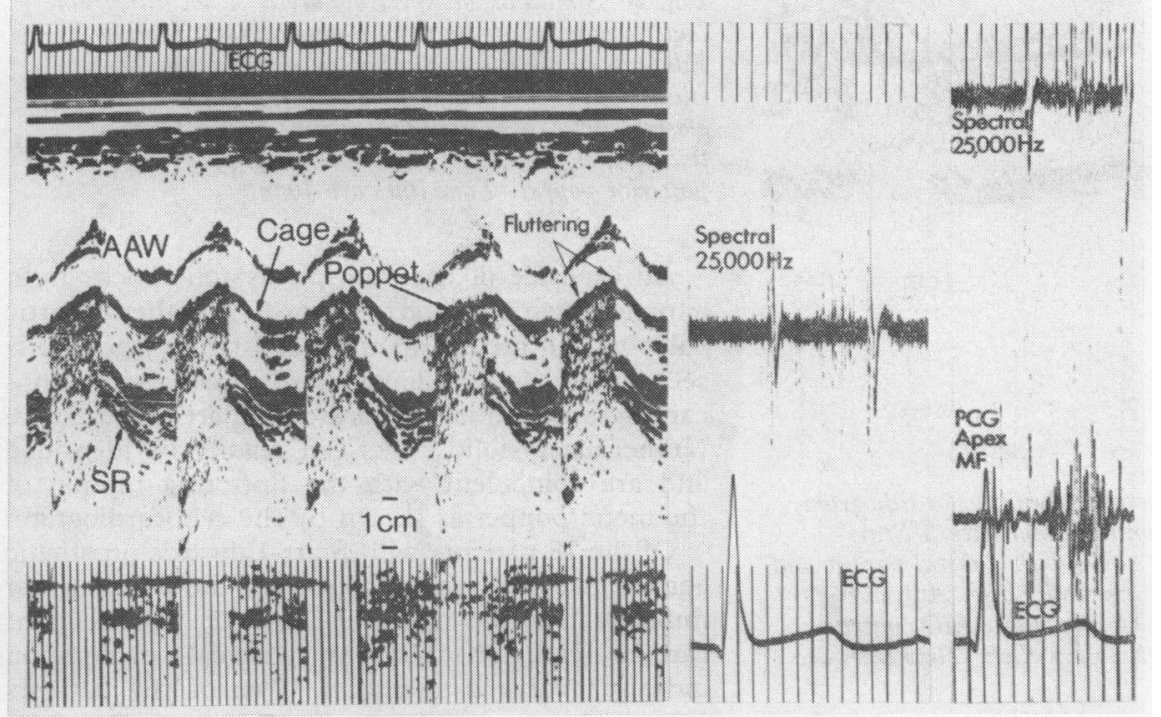

Fig. 4

Spectroanalysis, echocardiogram, phonocardiogram, and electrocardiogram from a patient with a StarrEdwards prosthetic aortic valve with a metal poppet. Note that the systolic murmur tends to obscure the recording of multiple systolic clicks on the phonocardiogram (PCG). The clicks are well recorded by spectroanalysis. $A A W$, anterior aortic wall. $S R$, suture ring. Time lines are $40 \mathrm{~ms}$. 


\section{Discussion}

The technique of simultaneous echocardiography, phonocardiography, and spectroanalysis has been used to determine the function of prosthetic heart valves as well as to elucidate the mechanism of the production of sounds from these valves (Hultgren and Hubis, 1965; Najmi and Segal, 1965; Boicourt et al., 1966). Cine studies of ball valve motion with a pulse simulator have shown bouncing or vibrating of the ball (Dayem and Raftery, 1966b), resulting in the production of such clicks. In patients with Starr-Edwards prosthetic aortic valves with non-metal (silastic) poppets, 2 or 3 systolic clicks of low intensity have been recorded in contrast to the high intensity multiple ejection clicks recorded from Starr-Edwards prosthetic valves with metal poppets. The 3 patients with Starr-Edwards prosthetic aortic valves with metal poppets in whom multiple systolic clicks were not heard or recorded were proved to have valve dysfunction by cardiac catheterisation or at operation.

The probable mechanism responsible for producing the multiple systolic clicks is the rapid fluttering motion of the poppet (Fig. 1). The first cardiac cycle shows the poppet fluttering only during the first half of systole corresponding with the recording of multiple systolic clicks during the same period.

During the second cardiac cycle, there is a fluttering motion of the poppet throughout systole; multiple systolic clicks are recorded coincident with the fluttering motion occupying all of systole. Reports by Dayem and Raftery (1966b) show that the poppet strikes the apex of the cage in early systole, and then collides randomly against the struts of the cage. There is some variability of this motion depending upon ejection velocity and heart rate. With rapid ejection times and fast heart rates, the ball may remain at the apex of the cage during most of the ejection period causing the systolic clicks to occur in early systole. Conversely, with a reduced ejection velocity and weaker beats, the poppet may be free to bounce and vibrate during the terminal part of systole, thereby producing additional clicks.

Systolic fluttering motion of the poppets shown by echocardiography is seen with non-metal as well as metal poppets. Exactly why metal poppets should produce easily audible multiple systolic clicks and silastic poppets do not is not entirely clear. However, this was a consistent finding in all patients with metal poppets who were examined, escept the 3 in whom subsequent investigation showed prosthetic valve dysfunction.

The advantage of spectroanalysis over phonocardiography in determining the presence of multi- ple systolic clicks is shown in Fig. 4. While multiple systolic clicks can be recorded by phonocardiography, a systolic murmur obscures their precise identification. By setting the centre band frequency for the spectroanalysis at $25000 \mathrm{~Hz}$, the systolic murmur was effectively filtered out and the clicks are clearly identified.

The auscultatory absence of multiple systolic clicks in patients with Starr-Edwards prosthetic aortic valves with metal poppets should alert the clinician to the possibility of valve dysfunction. However, in some patients, the detection of multiple systolic clicks may be obscured by the presence of a loud systolic ejection murmur. Thus, with the combined use of echocardiography, phonocardiography, and spectroanalysis, multiple systolic clicks in relation to fluttering motion of the poppet is a normal finding in patients with Starr-Edwards prosthetic aortic valves with metal poppets. The absence of multiple systolic clicks by spectroanalysis may indicate prosthetic valve dysfunction even when the cut-off frequencies of the opening and closing clicks are normal.

\section{References}

Boicourt, O. W., Bristow, J. D., Starr, A., and Griswold, H. E. (1966). A phonocardiographic study of patients with multiple Starr-Edwards prosthetic valves. British Heart fournal, 28, 531-538.

Dayem, M. K., and Raftery, E. B. (1966a). Mechanisms of production of heart sounds. American fournal of Cardiology, 18, 837-842.

Dayem, M. K., and Raftery, E. B. (1966b). Phonocardiogram of the ball-and-cage aortic valve prosthesis. British Heart fournal, 29, 446-452.

Delman, A. J. (1972). Aortic ball variance. American Heart fournal, 83, 291-292.

Gordon, R. F., Najmi, M., Kingsley, B., Segal, B. L., and Linhart, J. W. (1974). Spectroanalytic evaluation of aortic prosthetic valves. Chest, 66, 44-49.

Herr, R. H., Kloster, F. E., Sezai, Y., and Starr, A. (1967). Diagnosis and management of 'ball variance' following aortic valve replacement (abstract). Circulation, 35-36, Suppl. II, 141.

Hultgren, H. N., and Hubis, H. (1965). Phonocardiographic study of patients with the Starr-Edwards mitral valve prosthesis. American Heart fournal, 69, 306-319.

Hylen, J. C., Kloster, F. E., Herr, R. H., Hull, P. Q., Ames, A. W., Starr, A., and Griswold, H. E. (1968). Phonocardiographic diagnosis of aortic ball variance. Circulation, 38, $90-102$.

Hylen, J. C., Kloster, F. E., Herr, R. H., Starr, A., and Griswold, H. E. (1969). Sound spectrographic diagnosis of aortic ball variance. Circulation, 39, 848 .

Hylen, J. C., Kloster, F. E., Starr, A., and Griswold, H. E. (1970). Aortic ball variance: diagnosis and treatment. Annals of Internal Medicine, 72, 1-8.

Najmi, M., and Segal, B. L. (1965). Auscultatory and phonocardiographic findings in patients with prosthetic ballvalves. American fournal of Cardiology, 16, 794-799.

Waxler, E. B., Kingsley, B., and Segal, B. L. (1973). Evaluation of prosthetic valve function by octave band analysis. 
Fournal of the Medical Association of Georgia, 140, 140-143. Requests for reprints to Dr. Morris N. Kotler, Winters, W. L., Gimenez, J., and Soloff, L. A. (1967). Cardiovascular Institute, Hahnemann Medical Clinical application of ultrasound in the analysis of prosthetic ball valve function. American fournal of Cardiology, 19, 97-107. College and Hospital, 230 North Broad Street, Philadelphia, Pennsylvania 19102, U.S.A. 